\title{
Mid-Career Field Switches Reduce Gender Disparities in Academic Publishing ${ }^{1}$
}

Mike Thelwall, University of Wolverhampton, UK.

The continuing low proportions of females in most STEM fields in many countries is an ongoing concern, with no agreement about the fundamental causes or effective remedial actions. One previous study has found that professional females are more likely to switch from a (not necessarily academic) STEM career than professional females in comparable nonSTEM jobs, reducing the overall numbers of STEM females. This study investigates whether the same is true for long term academics, and hence could partly account for current gender disparities. Based on the Scopus subject categories of the first and last five publications 20012018 of people in 31 countries with publishing careers starting after 2000, female researchers switching fields mid-career tend to move to fields with fewer females, relative to males switching fields mid-career. Thus, mid-career field changes within academia do not help to explain continuing gender disparities in publishing and other explanations must be sought.

Keywords: Gender; careers; STEM; career changes; scientometrics.

\section{Introduction}

The low proportion of females in many Science, Technology, Engineering and Maths (STEM) fields in some countries has led to major funded initiatives (Rosser, Barnard, Carnes, \& Munir, 2019) or ongoing smaller initiatives (Best, Sanwald, Ihsen, \& Ittel, 2013) to redress the imbalance. There is controversy over whether the root causes of the lack of females in STEM fields are individual prejudices, systemic biases, or personal choice (e.g., Boynton, Georgiou, Reid, \& Govus, 2018), creating uncertainty about effective remedial actions.

In terms of individual prejudices, whilst one large study found a strong preference for female candidates in the USA (Williams \& Ceci, 2015), others have suggested that implicit prejudices disadvantage females (e.g., Reuben, Sapienza, \& Zingales, 2014). Systemic biases that disproportionately disadvantage females (e.g., Dahlberg, Demack, \& Bambra, 2007; Winslow \& Davis, 2016), such as inadequate support for childcare, part-time working and career breaks are important but not an obvious explanation for differences between fields in the ability to attract and retain females. One paper has argued that the key factor in the USA is the choice of major at university, suggesting that social influences and barriers during childhood are most important (Ceci, Ginther, Kahn, \& Williams, 2014). A choice-based theory to explain gendered broad patterns of (academic and non-academic) careers in the USA argues that female career goals are more likely to be communal whereas male career goals tend to be agentic, more focused on self-advancement (Diekman \& Steinberg, 2013; Diekman, Steinberg, Brown, Belanger, \& Clark, 2017; see also: Garibay, 2015; Kandiko Howson, Coate, $\&$ de St Croix, 2018). Thus, STEM careers perceived as less directly helpful to society would be less likely to match female goals than others, such as medicine. Conversely, males may be more attracted to STEM (and other) fields that promise high salaries and other status rewards.

There is some evidence of the stages that reduce the proportion of females in STEM fields, from childhood to late career. In the USA, girls are more likely to opt out of some STEMrelated activities before college (Cheryan, Ziegler, Montoya, \& Jiang, 2017). A low proportion

\footnotetext{
${ }^{1}$ Thelwall, M. (2020). Mid-career field switches reduce gender disparities in academic publishing. Scientometrics.
} 
of females study a STEM degree in the USA (Ceci, Ginther, Kahn, \& Williams, 2014), but a majority in the biological sciences (Stolzenberg, Eagan, Aragon, Cesar-Davis, Jacobo, Couch, \& Rios-Aguilar, 2019). There are only minor gender differences in the transition from a STEM degree to a STEM (academic or non-academic) job (Sassler, Glass, Levitte, \& Michelmore, 2017), and the rate of transition from STEM PhDs to a tenure track job is almost gender neutral in the USA, although males are more likely to obtain postdoctoral jobs (Shauman, 2017). Nevertheless, females leave STEM careers at a higher rate than males (e.g., Buse, Bilimoria, \& Perelli, 2013; Stephan \& Levin, 2005). This gap is particularly strong in engineering due to pay dissatisfaction and a lack of promotion opportunities (Hunt, 2016). Throughout academia, females seem to be underrepresented in senior positions (e.g., AdvanceHE, 2018; EU, 2018; HESA, 2019), so this does not seem to be a STEM-specific problem, although a study of a Swiss university has suggested that females are particularly disadvantaged when in a minority of under $15 \%$ (Schoen, Rost, \& Seidl, 2018).

The higher proportion of females leaving STEM careers cannot be fully accounted for by generic gender issues, such as career gaps or switching to part-time working for caring responsibilities. As evidence for this, a career analysis of females in (not necessarily academic) STEM careers found that they were much more likely to leave than females in comparable professional careers, irrespective of their job satisfaction (Glass, Sassler, Levitte, \& Michelmore, 2013). Two related explanations are that females may not feel a good match to a male-dominated environment (Schuster \& Martiny, 2017; Tellhed, Bäckström, \& Björklund, 2017) or may find it unfriendly (Crawford \& MacLeod, 1990). Within academia in the USA, STEM seems to be perceived as difficult to stay within by mothers (Kmec, 2013) and midcareer STEM females may also face challenges related to promotion and support (Hart, 2016), also suggesting that there might be a tendency for female academics to switch to non-STEM fields. This article investigates whether this is true for researchers that choose, and persist with, an academic research career. Whatever the cause, if academic STEM also has greater mid-career attrition of females, then this would be an issue that STEM gender parity initiatives could address.

Few articles seem to have mentioned the role of gender in mid-career academic field switches, and the exceptions have focused on narrow fields and not gender. For example, an analysis of Astronomy, Robotics and Ecology careers since the 1960s found that authors beginning their careers in later decades were much less likely to stay in these fields (Milojević, Radicchi, \& Walsh, 2018). The current paper addresses the lack of systematic evidence of gender difference in mid-career switches within academia with the following general research question: Do males and females making mid-career field switches tend to move away from fields dominated by the opposite gender? Whilst this may be a relatively minor aspect of gender differentiation in academic careers, it is nevertheless important, and the information may give insights into overall factors affecting career outcomes. This article is also written as a tribute to Professor Judit Bar-Ilan (1958-2019), who switched from a male field to a nearly gender-neutral field during her career. A statistical background of this switch in her country is in the Appendix.

\section{Methods}

The research design was to gather the career publications of a large sample of authors and then to compare the fields of their early publications with the fields of their latest publications to identify career shifts, analysing the results by gender. 


\section{Articles}

Scopus was chosen as the data source since it has greater coverage of academic literature than the Web of Science (Mongeon \& Paul-Hus, 2016). The period covered was 1996-2018, with the starting year 1996 coinciding with Scopus coverage expansion, since earlier data would be less reliable. Only documents of type journal article were included to focus on core research outputs. Academic identities were tracked by Scopus author IDs. These IDs are algorithmically defined, with the potential for author overriding to claim their own publications. Scopus author name disambiguation seems to be at least $98 \%$ accurate (Aman, 2018; Kawashima \& Tomizawa, 2015; Strotmann \& Zhao, 2012), but is probably less effective for females due to conventions in some cultures for females to change their last names after marriage (e.g., much of the English-speaking world, Russia, Germany, India and Japan but not most Spanish-speaking countries, Italy, The Netherlands, Korea, Portugal, Greece or China). There does not seem to be a solution to this problem, so it is accepted as a limitation.

\section{Authors}

All authors of an article were included rather than the main authors to include all types of contributions to research. It would also be reasonable to include only the first author, who is normally the main contributor to an article (Larivière, Desrochers, Macaluso, Mongeon, PaulHus, \& Sugimoto, 2016), and instead focus on the main contributors to research but this would be less clear-cut because a researcher may begin as a first author but remain in a field as a secondary author or vice versa.

Academics were analysed when they had published at least 10 journal articles indexed by Scopus 2001-2018 and had not published any Scopus indexed journal articles 1996-2000. Most people meeting this parameter seem likely to have their first major journal article within the dataset and to have a reasonably long academic career. This excludes less active researchers and people with short careers, such as PhD students moving to non-academic or teaching-focused jobs.

Author genders were detected by matching each first name with a list of first names that are at least $90 \%$ monogender in their country according to at least ten records in GenderAPI.com. The cut-off of $90 \%$ was chosen to ensure that the results were reasonably accurate. The gender detection rule was applied to the 31 countries with the most articles in Scopus. The $32^{\text {nd }}$ country, Malaysia, was chosen as the exclusion point because Malay first names are often the father's given name and therefore masculine for females. The total number of gendered authors with careers of at least 10 publications varied between 11,011 for Dentistry and 292,369 for Medicine (Table 1). 
Table 1. The number of gendered authors in the main data set (first publication after 2000, at least one of the first or last 5 articles within the broad field, affiliated with one of the top 31 countries in Scopus).

\begin{tabular}{|l|r|}
\hline Scopus broad field & Gendered authors \\
\hline Multidisciplinary & 65328 \\
\hline Agricultural and Biological Sciences & 149101 \\
\hline Arts and Humanities & 27061 \\
\hline Biochemistry, Genetics and Molecular Biology & 276469 \\
\hline Business, Management and Accounting & 25722 \\
\hline Chemical Engineering & 109304 \\
\hline Chemistry & 155384 \\
\hline Computer Science & 77665 \\
\hline Decision Sciences & 19169 \\
\hline Dentistry & 11011 \\
\hline Earth and Planetary Sciences & 58604 \\
\hline Economics, Econometrics and Finance & 17585 \\
\hline Energy & 57504 \\
\hline Engineering & 173346 \\
\hline Environmental Science & 103488 \\
\hline Health Professions & 35508 \\
\hline Immunology and Microbiology & 90741 \\
\hline Materials Science & 137081 \\
\hline Mathematics & 65636 \\
\hline Medicine & 292369 \\
\hline Neuroscience & 73956 \\
\hline Nursing & 34265 \\
\hline Pharmacology, Toxicology and Pharmaceutics & 83091 \\
\hline Physics and Astronomy & 160391 \\
\hline Psychology & 33378 \\
\hline Social Sciences & 65454 \\
\hline Veterinary & 18480 \\
\hline
\end{tabular}

\section{Career changes}

The first 5 articles in Scopus after the year 2000 were used to represent academics' initial field specialities and the last 5 articles in Scopus by the end of 2018 were taken to represent their mature or end career specialities. The number 5 was chosen to represent a substantial part of the early career of a researcher, probably covering their $\mathrm{PhD}$ and early postdoctoral work. Changes in the fields between these two sets were used as a mid-career shift indicator. This is a simplification because a researcher may have multiple field shifts in their career and may publish interdisciplinary research or monodisciplinary research in interdisciplinary journals that would be classified within all the fields of the interdisciplinary journal. Moreover, a researcher may switch field before their fifth publication. These restrictions apply to both genders analysed, however, so the errors should tend to cancel out when the data is aggregated. 
- An author is classed as joining a field if they published none of their first five articles in the field and at least one of their last five articles in the field.

- An author is classed as leaving a field if they published at least one of their first five articles in the field and none of their last five articles in the field.

- An article is classed as staying in a field if they published at least one of their first five articles in the field and at least one of their last five articles in the field.

For each gender and field, the movement into a field is defined as follows, where Join, Leave and Stay are the numbers of authors fitting into each category with the above definition.

$$
\text { Net career shift }=(\text { Join }- \text { Leave }) /(\text { Join }+ \text { Leave }+ \text { Stay })
$$

Here, a positive fraction indicates a net move into a field due to mid-career changes, whereas a negative fraction indicates a net move away from the field due to mid-career changes. The core indicator of gender shift is the difference between the male and female net career shifts for a single field:

\section{Female net career shift - male net career shift}

Thus, a positive value indicates that females move into a field more than males, or that males move away from a field more than females. This formula is for gender differences in career shifts and therefore ignores the relative numbers of males and females with shifting careers. This method was used rather than focusing on net career shifts for females alone because the size of Scopus categories changes over time, so an apparent female career shift could be due to an expansion or contraction in the number of articles indexed by Scopus in that field.

\section{Primary test}

The relationship between mid-career field changes and gender disparities was calculated by correlating the proportions of females in fields with the difference between the female and male career shifts (Female net career shift - male net career shift) for the same fields. A positive correlation indicates that fields with a higher proportion of females would tend to gain from mid-career shifts (ignoring the absolute numbers of males and females involved) and fields with a lower proportion of females would tend to lose from mid-career shifts. A negative correlation indicates the opposite. Pearson correlations were used because the data was not highly skewed and rank correlations (e.g., Spearman) would not give fine-grained results.

\section{Robustness checks}

To test whether the conclusions would change with altered data set parameters, the analysis was repeated with the following variations.

- Using the first and last article instead of the first and last 5 articles to define the initial and $\mathrm{mid} /$ late career field.

- Starting the analysis at 2011 instead of 2001 (and excluding academics that had published before the revised start date).

- Analysing first authors only, ignoring other author contributions.

- Analysing individual countries instead of all countries combined. 


\section{Results}

Based on the heuristics for academics having mid-career changes after (most recent 5 Scopus articles) starting their career (first 5 Scopus articles), substantial numbers join, leave and stay in all disciplines, although the proportions vary (Figure 1). Evaluating career changes between the first article and most recent article only, the proportion of authors staying in a field shrinks and the Multidisciplinary classification has almost no authors staying (Figure 2).

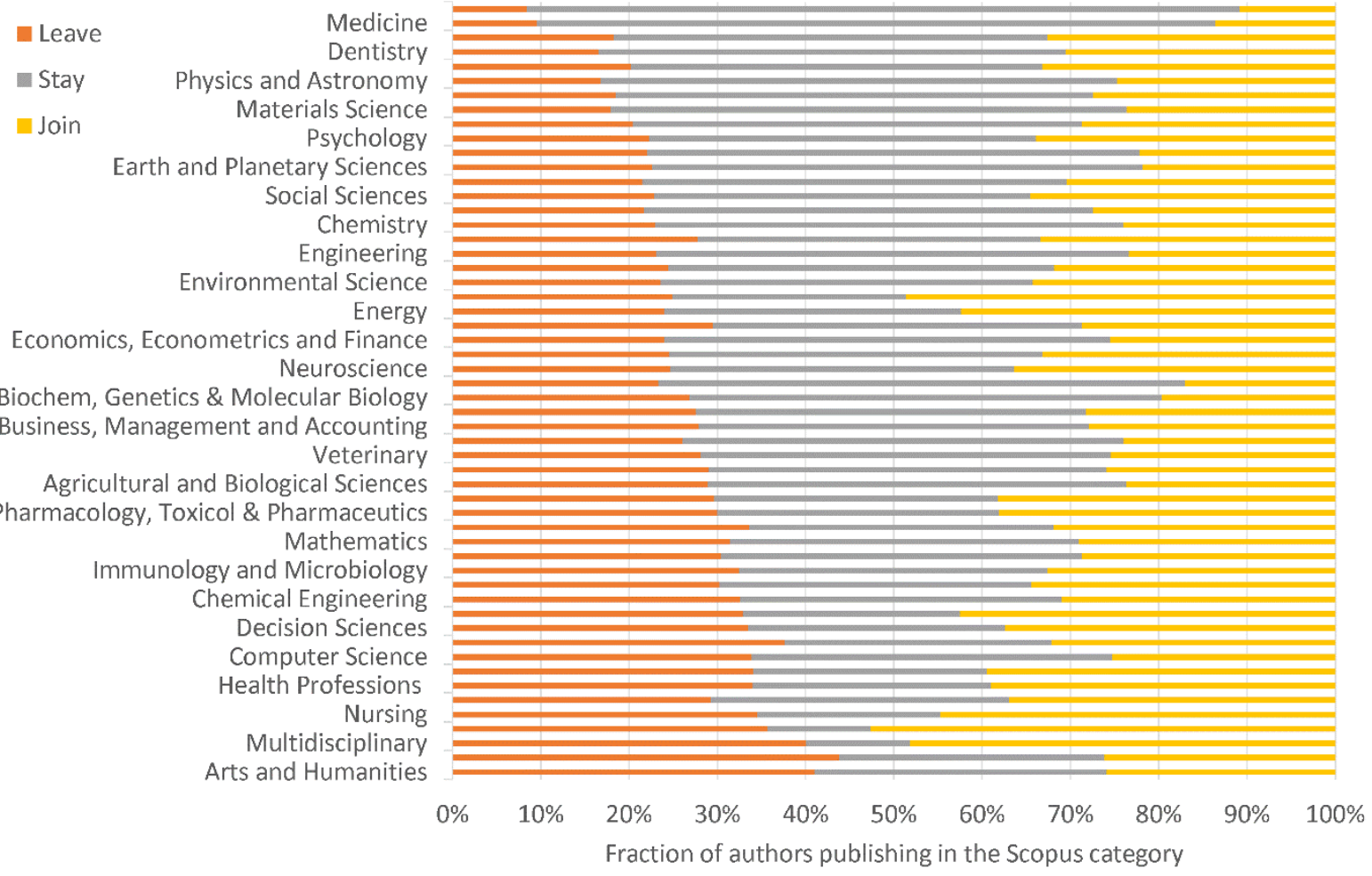

Figure 1. The share of authors that leave stay or join a broad field, by gender. All authors, all countries, 2001 cut-off, first against last 5 articles. Each broad field had two stacked bars: the upper one is for males and the lower is for females. Fields are sorted in order of increasing male leave proportions. 


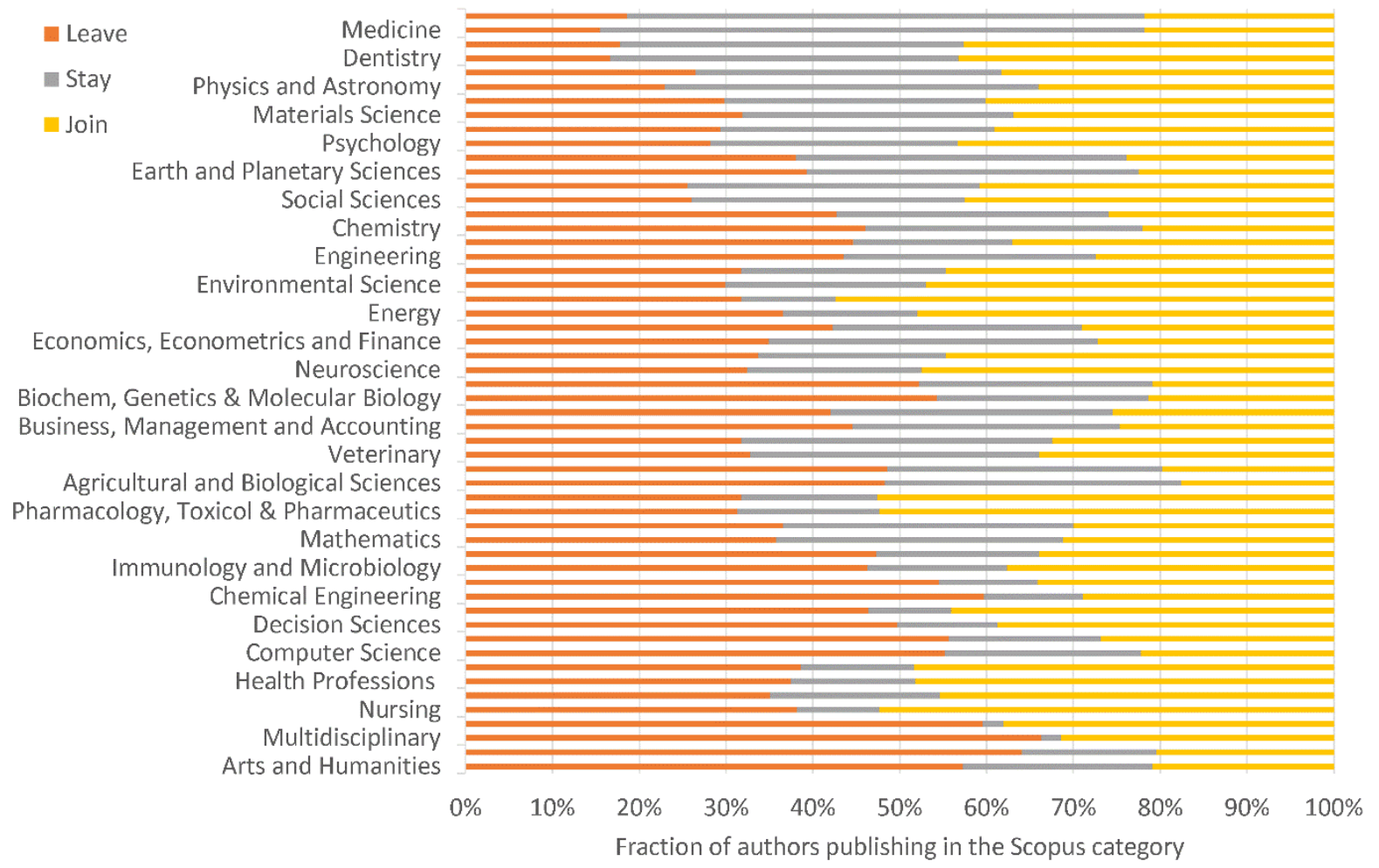

Figure 2. The share of authors that leave stay or join a broad field, by gender. All authors, all countries, 2001 cut-off, first against last 1 article. Each broad field had two stacked bars: the upper one is for males and the lower is for females. Each broad field had two stacked bars: the upper one is for males and the lower is for females. Fields are sorted in the same order as for Figure 1.

For the main data set there is a negative correlation of -0.669 between the proportion of female researchers and female net career shifts subtract male net career shifts (Table 2). There is a thus a substantial tendency for mid-career changes to move researchers towards fields in which their gender is less represented, giving a negative answer to the research question. The same is true to a lesser extent (correlation -0.386) if only the main authors of research are considered.

For robustness checking, there are also strong negative correlations for all authors for the top five countries analysed separately, and if the starting year is increased to 2011 (Table 2). Considering first authors only, the results change for the USA because it has a tiny (negative) correlation and for Japan because it has a tiny positive correlation. Thus, for first authors in these two countries, mid-career gender shifts for first authors are similar for both genders studied.

Also for robustness checking, if only the first and last articles are considered when evaluating mid-career shifts, the situation for all authors is similar but that for first authors changes. For Japan, mid-career shifts for first authors based on their first and last articles tend to move authors towards fields where their gender is more prevalent (correlation 0.320) and the USA, China and UK have tiny correlations.

In summary, the results for all authors are robust to changes in the key parameters, but the results for first authors are not. The international variations in the first author results suggest that authorship order strategies may vary internationally. For example, it may be 
more common in some countries for collaborators to exchange the chance to be the main order, and team science with pre-defined orders may be common in other countries.

Table 2. Pearson correlations between the proportion of female authors and the female net career shift subtract the male career shift ( $n=27$ fields).

\begin{tabular}{|l|l|l|l|l|l|}
\hline \multirow{2}{*}{ Dataset } & \multirow{2}{*}{ Start year } & \multicolumn{2}{l|}{ First and last 5 articles } & \multicolumn{2}{l|}{ First and last article } \\
\cline { 3 - 6 } & & All authors & First author & All authors & First author \\
\hline 31 countries & 2001 & -0.669 & -0.386 & -0.593 & -0.482 \\
\hline 31 countries & 2011 & -0.441 & -0.225 & -0.454 & -0.313 \\
\hline USA & 2001 & -0.686 & -0.085 & -0.515 & -0.065 \\
\hline China & 2001 & -0.345 & -0.314 & -0.196 & 0.103 \\
\hline UK & 2001 & -0.514 & -0.201 & -0.374 & -0.081 \\
\hline Germany & 2001 & -0.469 & -0.354 & -0.568 & -0.527 \\
\hline Japan & 2001 & -0.413 & 0.095 & -0.369 & 0.320 \\
\hline
\end{tabular}

The net career shifts for individual fields for the main results (Figure 3), for first authors (Figure 4) and some of the robustness checks (Figures 5-12) can be read from the scatterplots. The female author shares are approximate since they do not adjust for the possibility that one gender is easier to detect through first names.

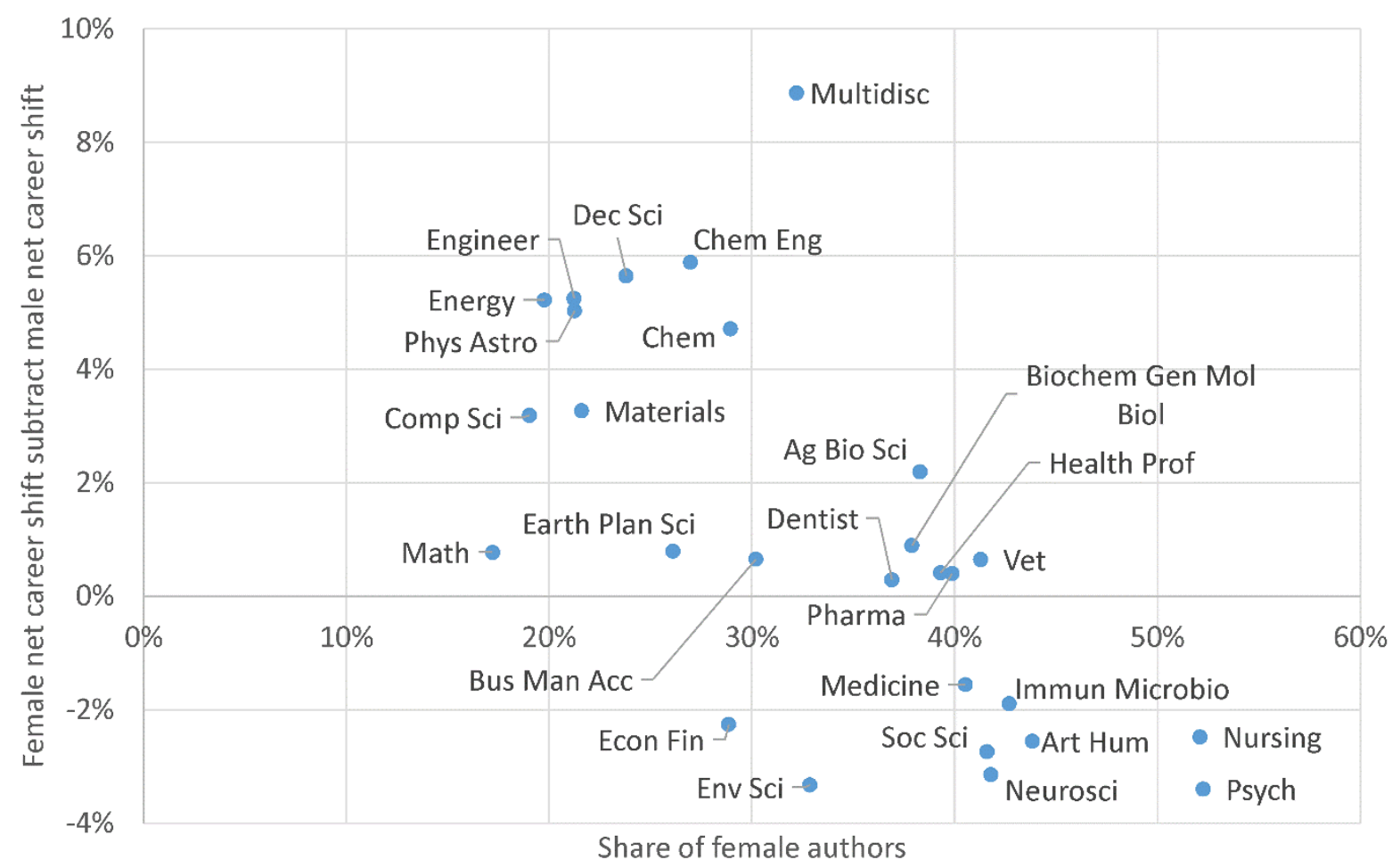

Figure 3. The relative mid-career shift of females into each field compared to males, against the proportion of females in the field. All authors, all countries, 2001 cut-off, first against last 5 articles. 


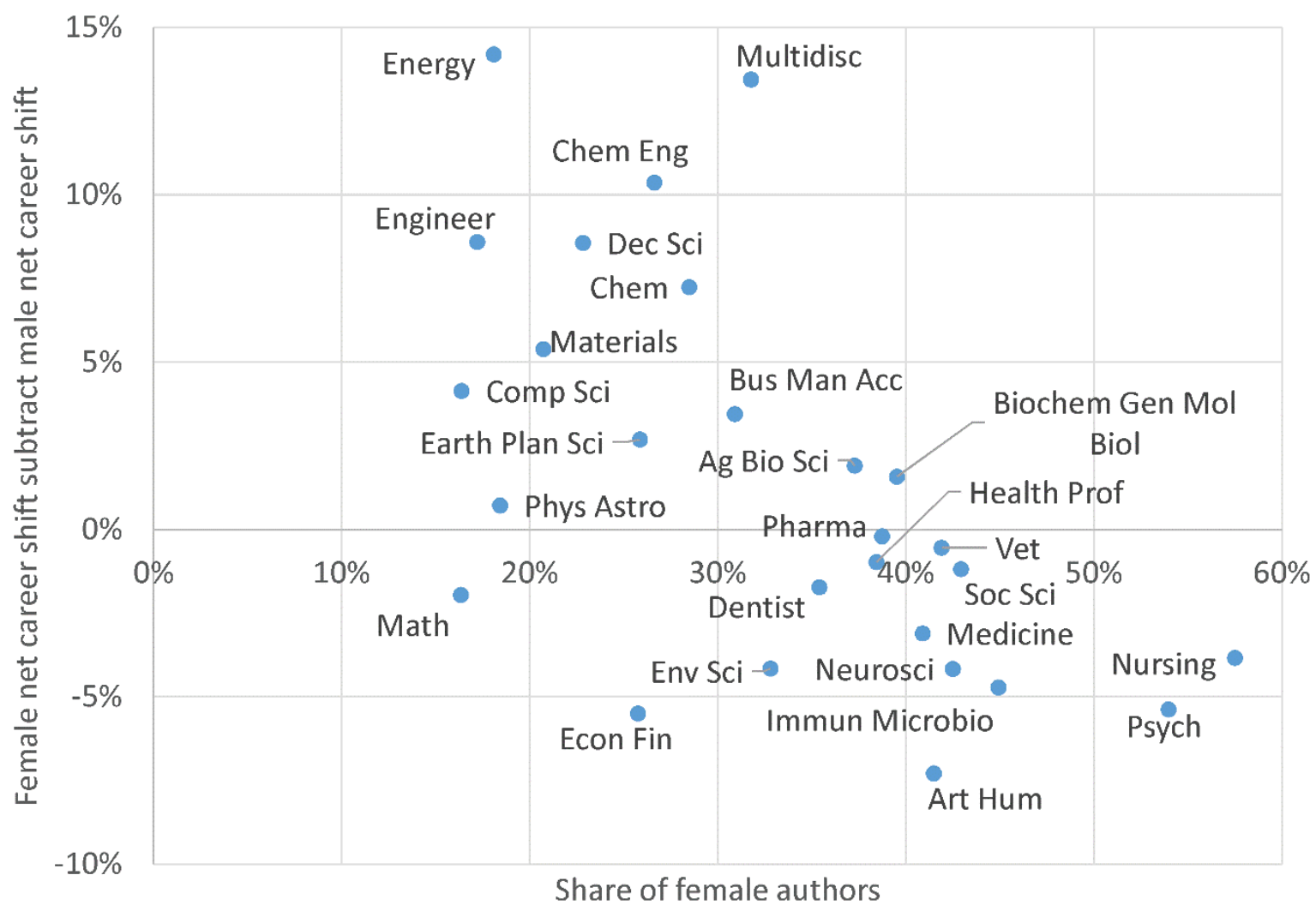

Figure 4. The relative mid-career shift of females into each field compared to males, against the proportion of females in the field. All authors, all countries, 2001 cut-off, first against last 1 article.

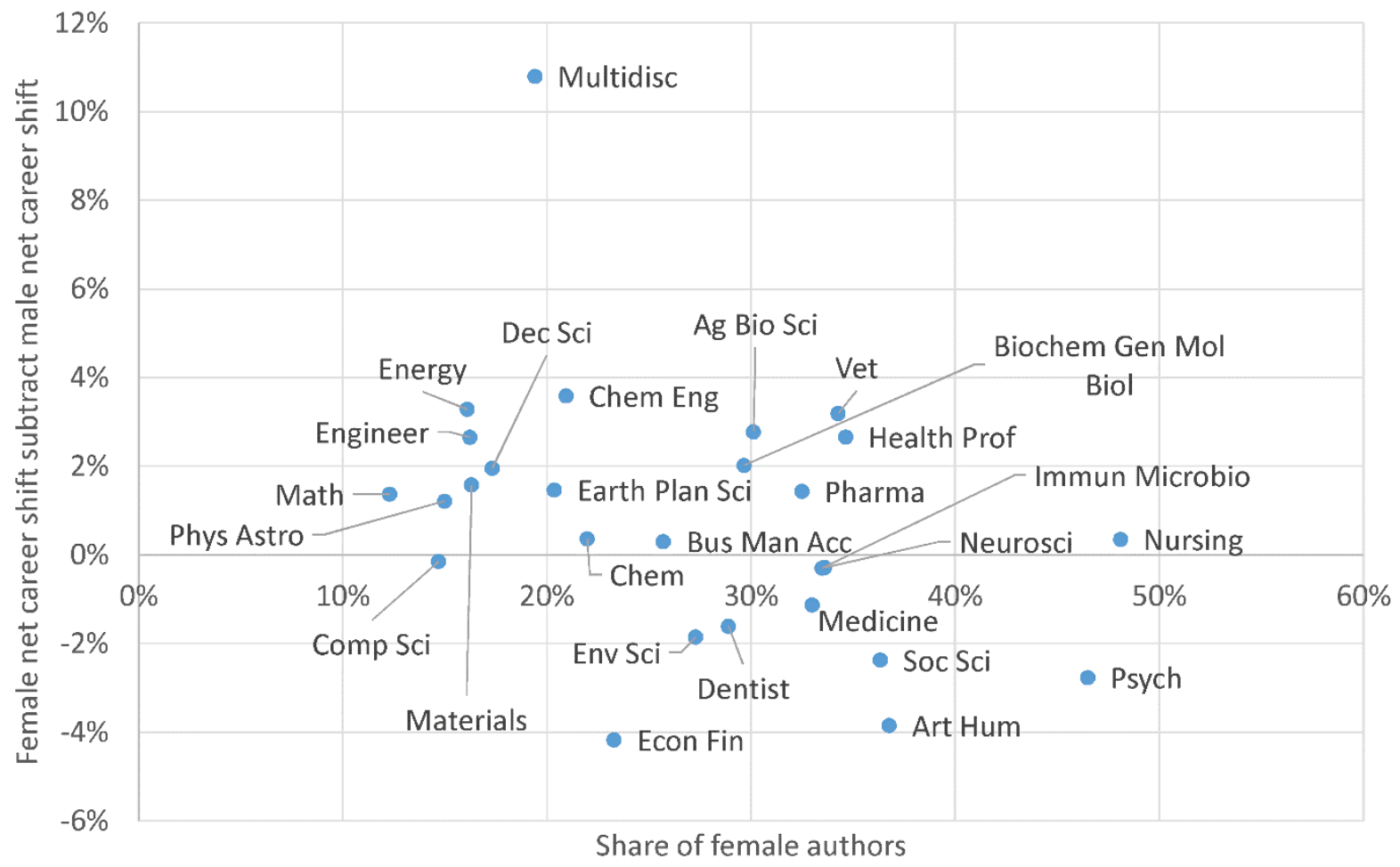

Figure 5. The relative mid-career shift of females into each field compared to males, against the proportion of females in the field. First authors, all countries, 2001 cut-off, first against last 5 articles. 


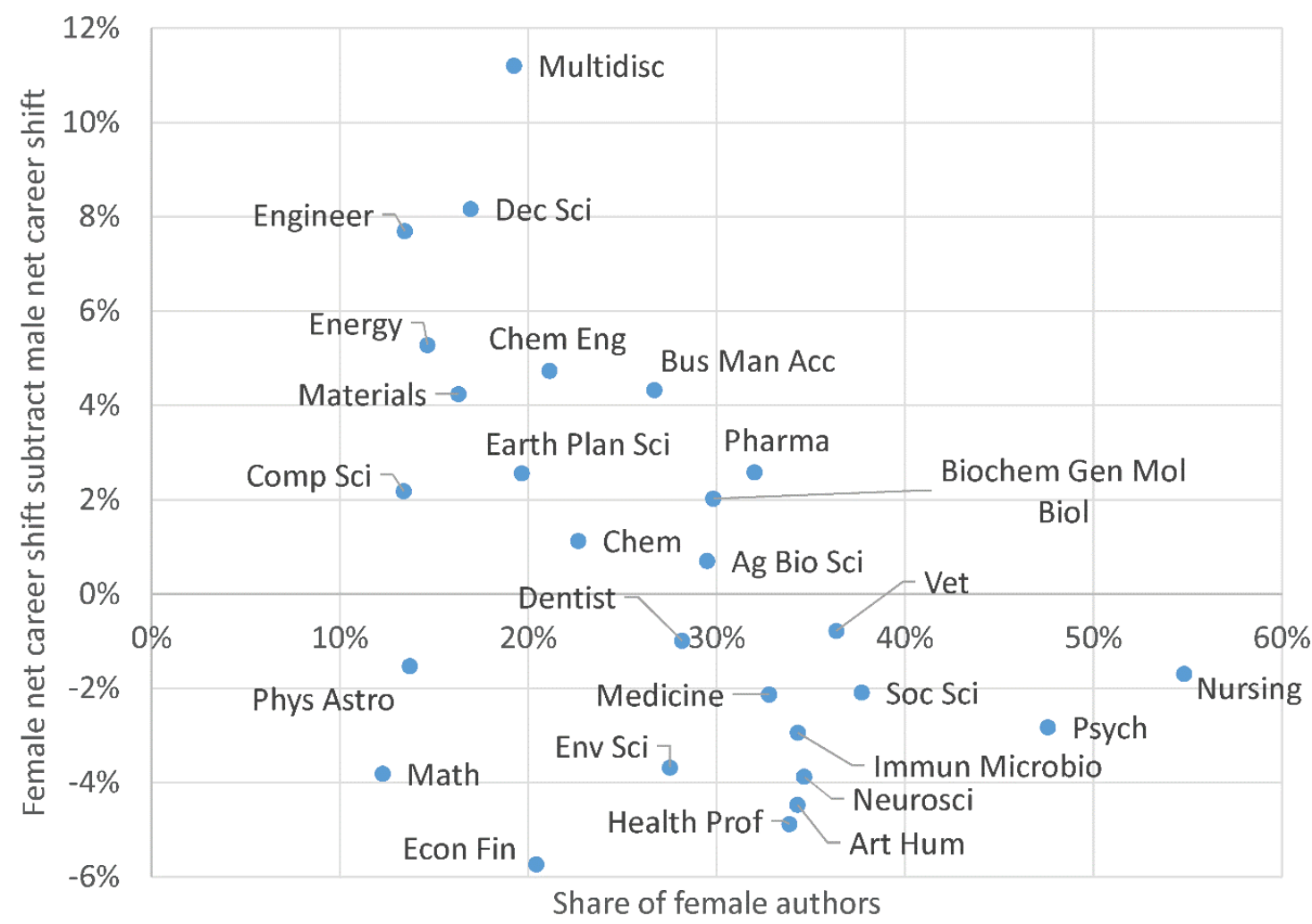

Figure 6. The relative mid-career shift of females into each field compared to males, against the proportion of females in the field. First authors, all countries, 2001 cut-off, first against last 1 article.

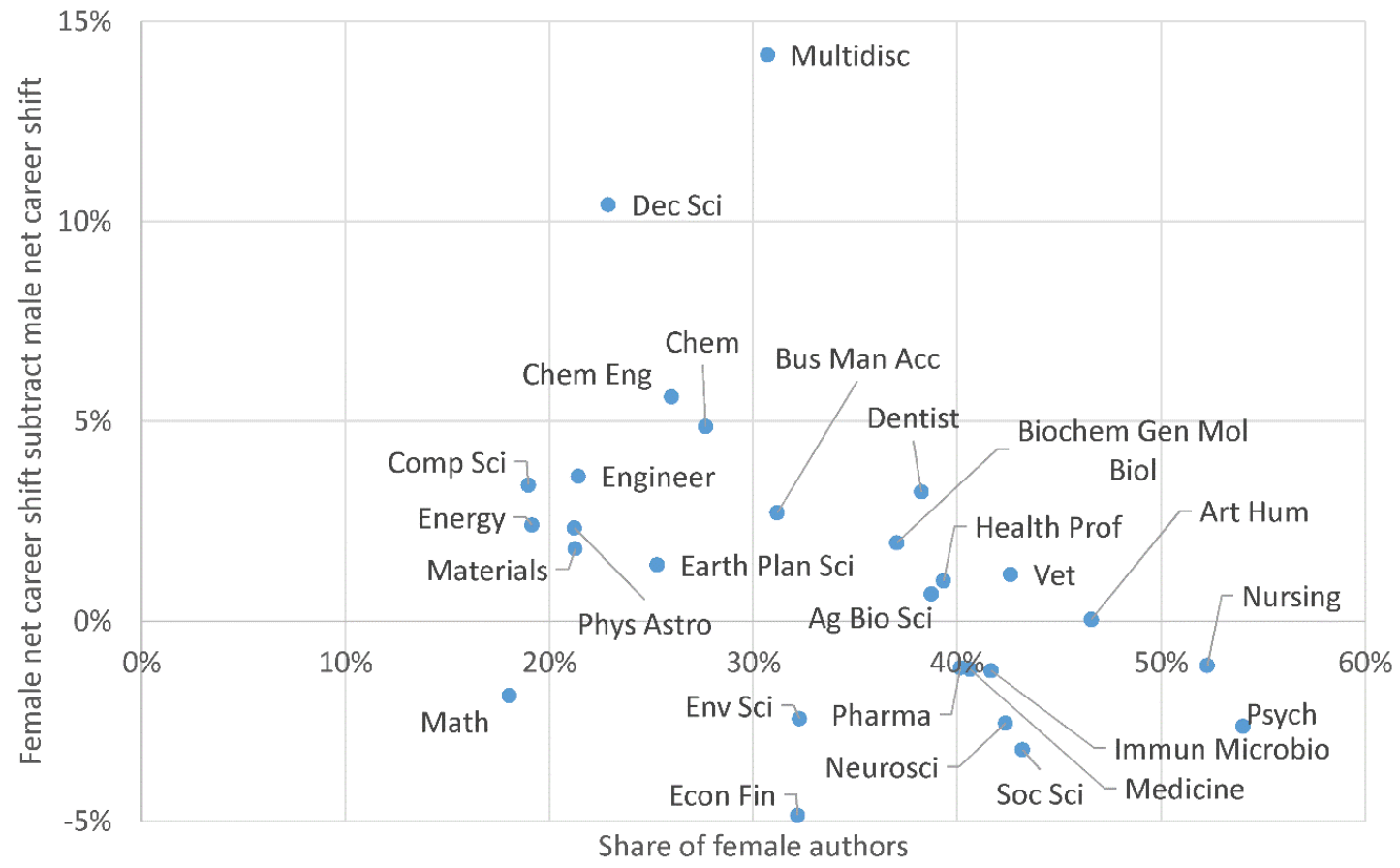

Figure 7. The relative mid-career shift of females into each field compared to males, against the proportion of females in the field. All authors, all countries, 2011 cut-off, first against last 5 articles. 


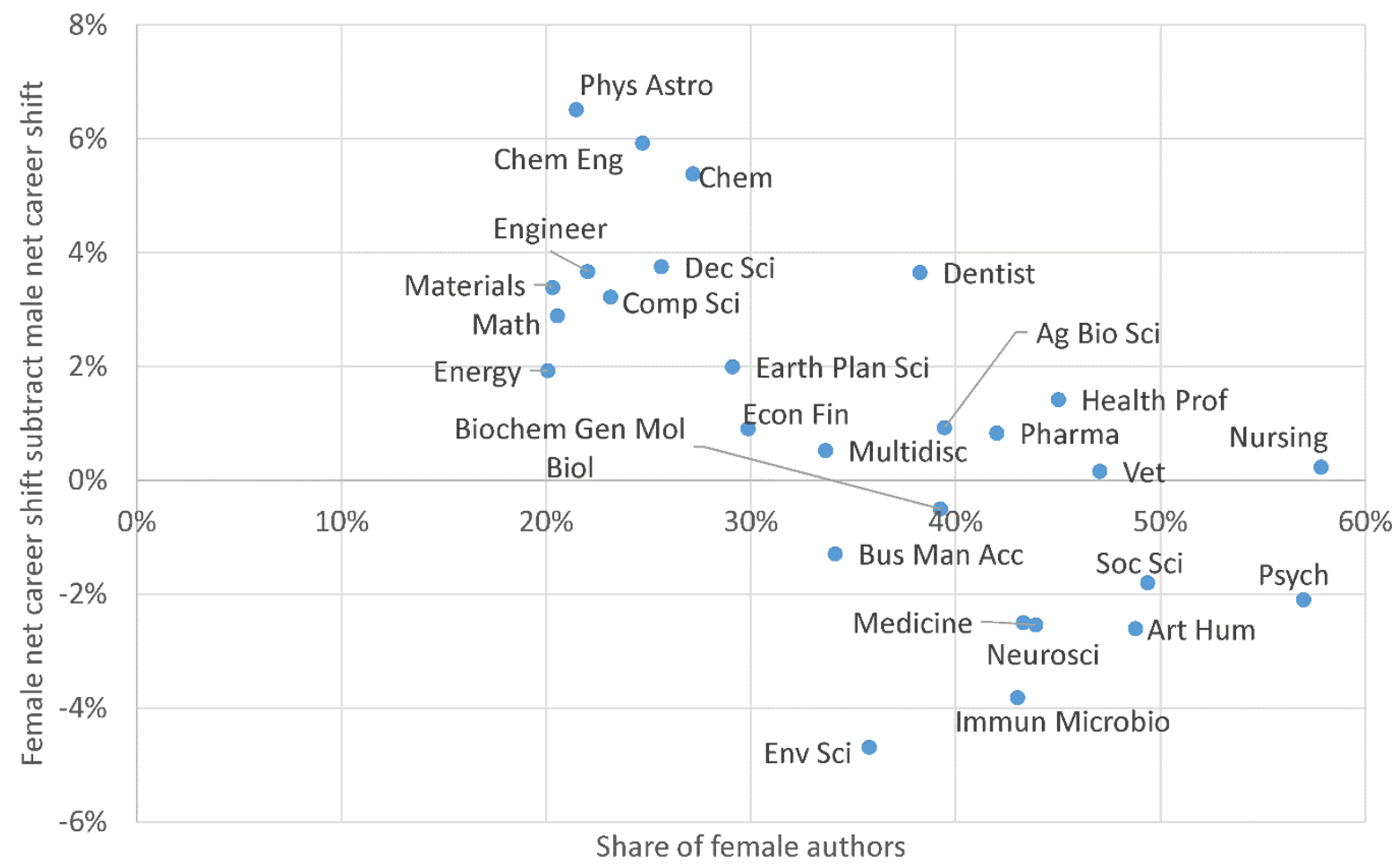

Figure 8. The relative mid-career shift of females into each field compared to males, against the proportion of females in the field. All authors, USA, 2001 cut-off, first against last 5 articles.

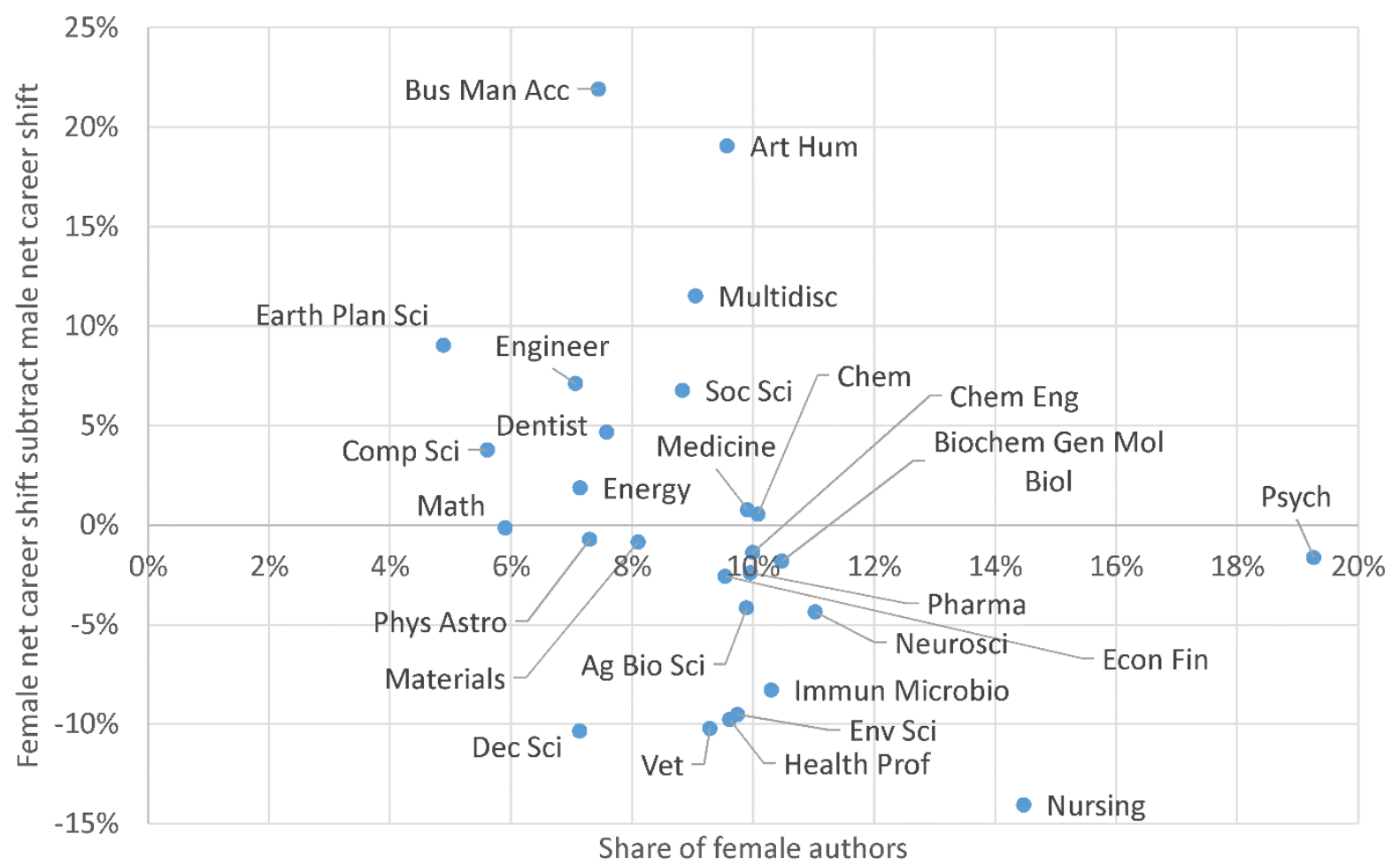

Figure 9. The relative mid-career shift of females into each field compared to males, against the proportion of females in the field. All authors, China, 2001 cut-off, first against last 5 articles. 


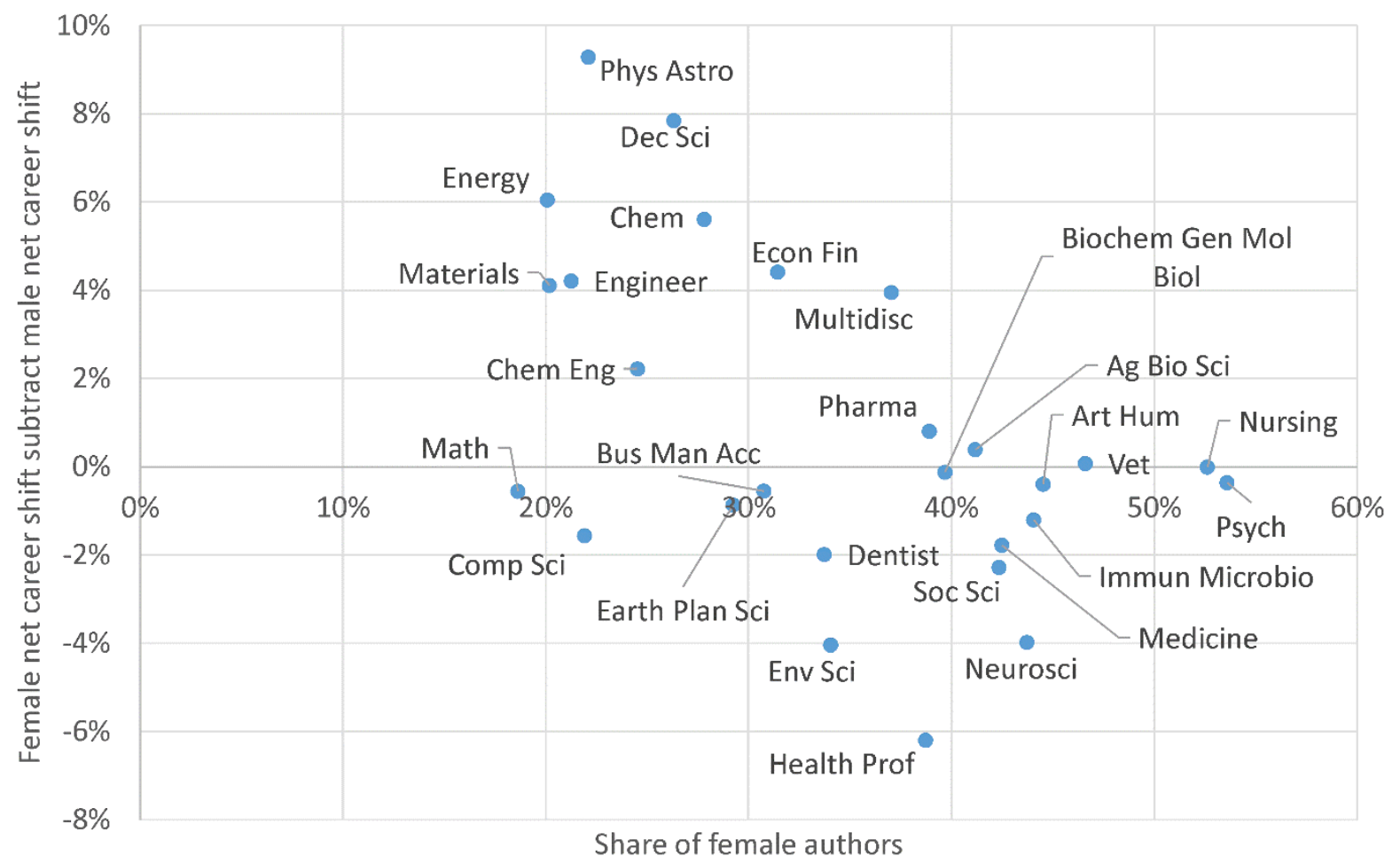

Figure 10. The relative mid-career shift of females into each field compared to males, against the proportion of females in the field. All authors, UK, 2001 cut-off, first against last 5 articles.

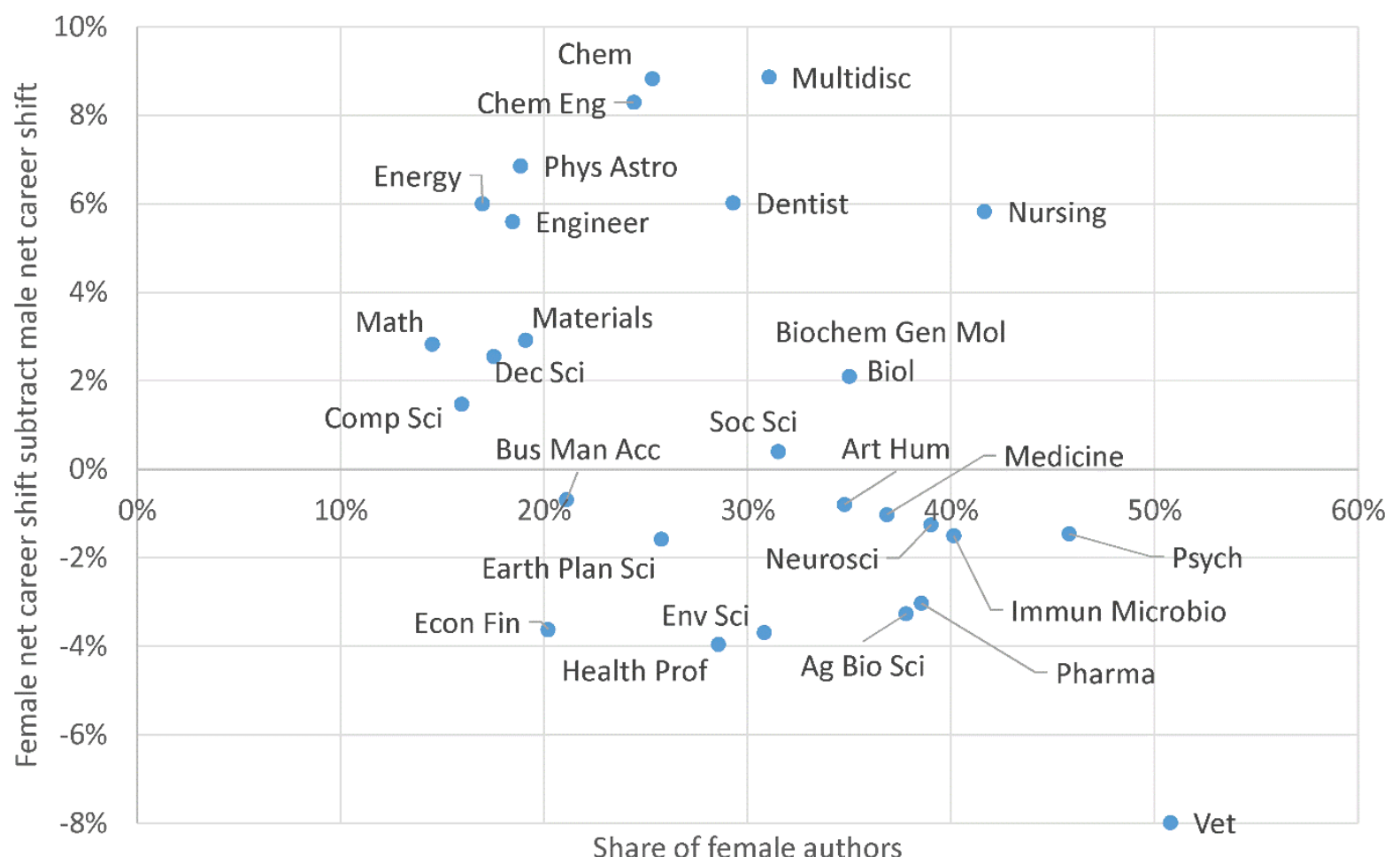

Figure 11. The relative mid-career shift of females into each field compared to males, against the proportion of females in the field. All authors, Germany, 2001 cut-off, first against last 5 articles. 


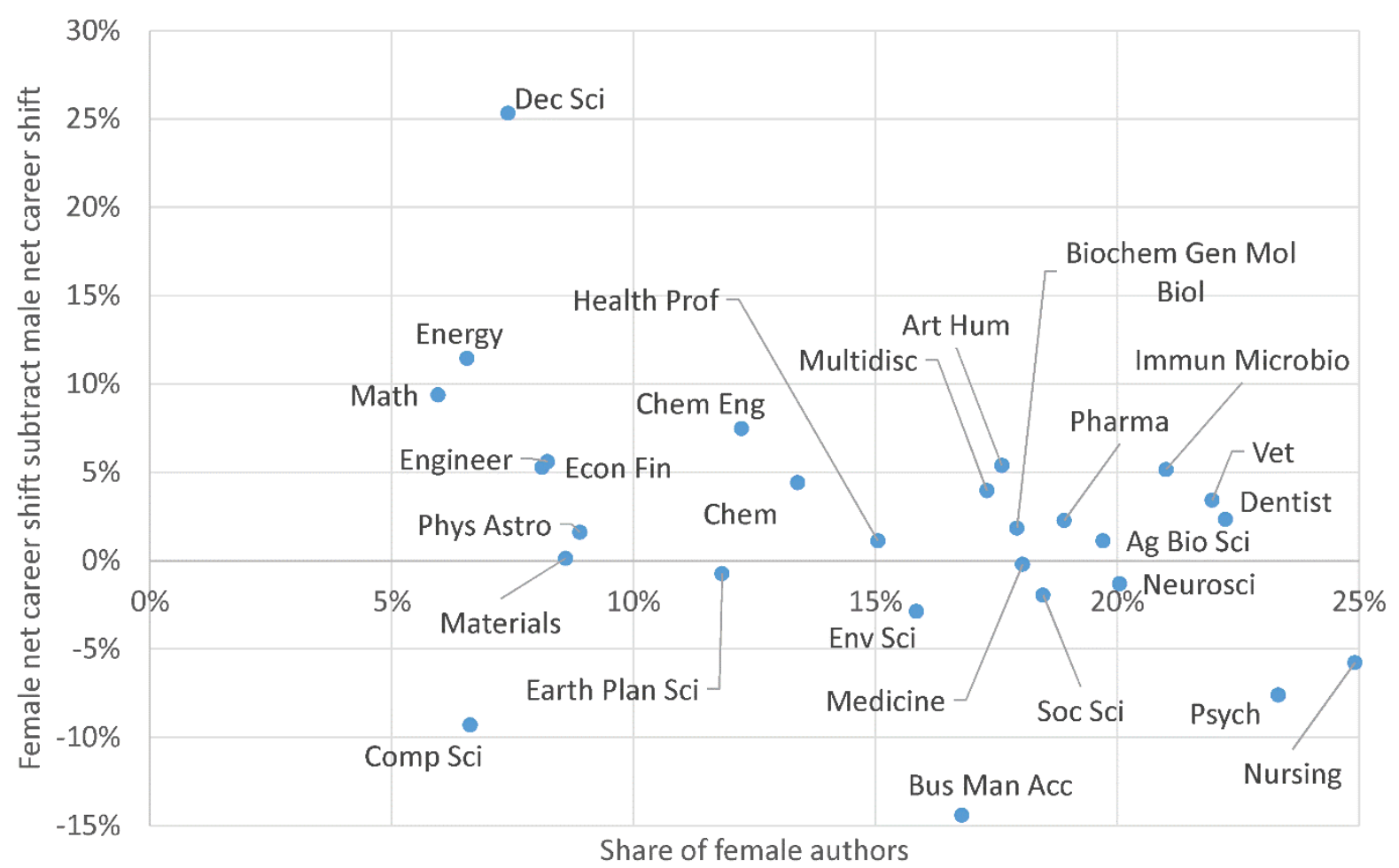

Figure 12. The relative mid-career shift of females into each field compared to males, against the proportion of females in the field. All authors, Japan, 2001 cut-off, first against last 5 articles.

\section{Limitations}

This study has several major limitations. Publication-based analyses do not reflect teachingfocused academic careers, which are disproportionately female in some countries (Ceci \& Williams, 2011). The data does not include non-Scopus and non-article document types (e.g., books, book chapters, conference papers) that some academics may switch to or from writing. Academics are increasingly multidisciplinary and apparent field changes may reflect contributions to multidisciplinary projects instead. Academic fields change their nature and definitions over time, as do journals, so the Scopus categories are an oversimplification. If these factors affect one gender more than another then this would produce second order biases in the results.

\section{Discussion}

The results are the opposite to that predicted from a professional career analysis of that found females to be more likely to leave (male dominated) STEM careers than comparable female professionals (Glass, Sassler, Levitte, \& Michelmore, 2013). All STEM fields have a net female gain (in terms of the formula used) except the relatively female category Immunology and Microbiology (points above the $x$ axis in Figure 3 ). Thus, it seems that academic STEM careers are better able to retain (publishing, long term academic career) females than comparable non-academic STEM careers. The following may be partial explanations for this.

- Initiatives to retain academic STEM females (Rosser, Barnard, Carnes, \& Munir, 2019) may be working to some extent, for example by shifting STEM cultures so that the lack of females is recognised to be a problem. 
- Academic STEM females that no longer want to work with the field may stay within academia but switch to a non-publishing, teaching focused career. Longitudinal CVbased career data would be needed to test this.

- Academic STEM research usually takes place within a university environment, where females may be able to develop strategies to cope with undesired STEM cultures, such as connecting with other females in non-STEM areas. This contrasts with nonacademic STEM workplaces, some of which are small and more focused.

- Increasing amounts of multidisciplinary research may give females dissatisfied with STEM the opportunity to collaborate with researchers in other fields.

\section{Conclusions}

The results are positive for STEM and other fields lacking females in the sense that they can expect to be net gainers of female researchers from mid-career changes, at least in terms of academics that continue in the same career and continue to publish. They are also positive in the sense of suggesting that academic STEM may not alienate females that choose it as a career, possibly in contrast the wider STEM employment. Thus, there does not seem to be a universal problem for STEM-trained committed female academics to try to move into more female fields. Retaining STEM females within academia is therefore less important than recruiting them in the first place for STEM gender initiatives, such as ADVANCE or Athena SWAN, unless other evidence shows that STEM females often leave academia rather than switching fields.

\section{References}

AdvanceHE (2018). Staff statistical report 2018. https://www.advancehe.ac.uk/sites/default/files/2019-05/2018-06-ECU_HE-stats-report_staff_v5compressed.pdf

Aman, V. (2018). Does the Scopus author ID suffice to track scientific international mobility? A case study based on Leibniz laureates. Scientometrics, 117(2), 705-720.

Best, K. L., Sanwald, U., Ihsen, S., \& Ittel, A. (2013). Gender and STEM in Germany: Policies enhancing women's participation in academia. International Journal of Gender, Science and Technology, 5(3), 292-304.

Boynton, J. R., Georgiou, K., Reid, M., \& Govus, A. (2018). Gender bias in publishing. The Lancet, 392(10157), 1514-1515.

Buse, K., Bilimoria, D., \& Perelli, S. (2013). Why they stay: Women persisting in US engineering careers. Career Development International, 18(2), 139-154.

Ceci, S. J., Ginther, D. K., Kahn, S., \& Williams, W. M. (2014). Women in academic science: A changing landscape. Psychological Science in the Public Interest, 15(3), 75-141.

Ceci, S. J., \& Williams, W. M. (2011). Understanding current causes of women's underrepresentation in science. Proceedings of the National Academy of Sciences, 108(8), 3157-3162.

Cheryan, S., Ziegler, S. A., Montoya, A. K., \& Jiang, L. (2017). Why are some STEM fields more gender balanced than others? Psychological Bulletin, 143(1), 1-35.

Crawford, M., \& MacLeod, M. (1990). Gender in the college classroom: An assessment of the "chilly climate" for women. Sex Roles, 23(3-4), 101-122. 
Dahlberg, L., Demack, S., \& Bambra, C. (2007). Age and gender of informal carers: a population-based study in the UK. Health \& Social Care in the Community, 15(5), 439445.

Diekman, A. B., Steinberg, M., Brown, E. R., Belanger, A. L., \& Clark, E. K. (2017). A goal congruity model of role entry, engagement, and exit: Understanding communal goal processes in STEM gender gaps. Personality and Social Psychology Review, 21(2), 142175.

Diekman, A. B., \& Steinberg, M. (2013). Navigating social roles in pursuit of important goals: A communal goal congruity account of STEM pursuits. Social and Personality Psychology Compass, 7(7), 487-501.

EU (2018). She figures 2018. https://publications.europa.eu/en/publication-detail//publication/9540ffa1-4478-11e9-a8ed-01aa75ed71a1/language-en

Garibay, J. C. (2015). STEM students' social agency and views on working for social change: Are STEM disciplines developing socially and civically responsible students? Journal of Research in Science Teaching, 52(5), 610-632.

Glass, J. L., Sassler, S., Levitte, Y., \& Michelmore, K. M. (2013). What's so special about STEM? A comparison of women's retention in STEM and professional occupations. Social Forces, 92(2), 723-756.

Hart, J. (2016). Dissecting a gendered organization: Implications for career trajectories for mid-career faculty women in STEM. The Journal of Higher Education, 87(5), 605-634.

HESA (2019). Higher Education Staff Statistics: UK, 2017/18. https://www.hesa.ac.uk/news/24-01-2019/sb253-higher-education-staff-statistics

Hunt, J. (2016). Why do women leave science and engineering? ILR Review, 69(1), 199-226.

Kandiko Howson, C. B., Coate, K., \& de St Croix, T. (2018). Mid-career academic women and the prestige economy. Higher Education Research \& Development, 37(3), 533-548.

Kawashima, H., \& Tomizawa, H. (2015). Accuracy evaluation of Scopus Author ID based on the largest funding database in Japan. Scientometrics, 103(3), 1061-1071.

$\mathrm{Kmec}$, J. A. (2013). Why academic STEM mothers feel they have to work harder than others on the job. International Journal of Gender, Science and Technology, 5(2), 79-101.

Larivière, V., Desrochers, N., Macaluso, B., Mongeon, P., Paul-Hus, A., \& Sugimoto, C. R. (2016). Contributorship and division of labor in knowledge production. Social Studies of Science, 46(3), 417-435.

Milojević, S., Radicchi, F., \& Walsh, J. P. (2018). Changing demographics of scientific careers: The rise of the temporary workforce. Proceedings of the National Academy of Sciences, 115(50), 12616-12623.

Mongeon, P., \& Paul-Hus, A. (2016). The journal coverage of Web of Science and Scopus: a comparative analysis. Scientometrics, 106(1), 213-228.

Reuben, E., Sapienza, P., \& Zingales, L. (2014). How stereotypes impair women's careers in science. Proceedings of the National Academy of Sciences, 111(12), 4403-4408.

Rosser, S. V., Barnard, S., Carnes, M., \& Munir, F. (2019). Athena Swan and Advance: effectiveness and lessons learned. The Lancet, 393(10171), 604-608.

Sassler, S., Glass, J., Levitte, Y., \& Michelmore, K. M. (2017). The missing women in STEM? Assessing gender differentials in the factors associated with transition to first jobs. Social Science Research, 63, 192-208.

Schoen, C., Rost, K., \& Seidl, D. (2018). The influence of gender ratios on academic careers: Combining social networks with tokenism. PloS One, 13(11), e0207337. 
Schuster, C., \& Martiny, S. E. (2017). Not feeling good in STEM: Effects of stereotype activation and anticipated affect on women's career aspirations. Sex Roles, 76(1-2), 40-55.

Shauman, K. (2017). Gender differences in the early employment outcomes of STEM doctorates. Social Sciences, 6(1), 24.

Stephan, P. E., \& Levin, S. G. (2005). Leaving careers in IT: Gender differences in retention. The Journal of Technology Transfer, 30(4), 383-396.

Stolzenberg, E. B., Eagan, K. M., Aragon, M. C., Cesar-Davis, N., Jacobo, S., Couch, V., \& RiosAguilar, C. (2019). The American Freshman: National Norms Fall 2017. Los Angeles: Higher Education Research Institute, UCLA.

Strotmann, A., \& Zhao, D. (2012). Author name disambiguation: What difference does it make in author-based citation analysis? Journal of the American Society for Information Science and Technology, 63(9), 1820-1833.

Tellhed, U., Bäckström, M., \& Björklund, F. (2017). Will I fit in and do well? The importance of social belongingness and self-efficacy for explaining gender differences in interest in STEM and HEED majors. Sex Roles, 77(1-2), 86-96.

Williams, W. M., \& Ceci, S. J. (2015). National hiring experiments reveal 2:1 faculty preference for women on STEM tenure track. Proceedings of the National Academy of Sciences, 112(17), 5360-5365.

Winslow, S., \& Davis, S. N. (2016). Gender inequality across the academic life course. Sociology Compass, 10(5), 404-416.

\section{Appendix Gender Differences in Academic Publishing During the Career of Judit Bar-llan}

Professor Judit Bar-Ilan lived and worked in Israel throughout her career. Within Israel, the proportion of female first-authored articles increased from 26.3\% (2.8 male articles per female article) in 1996-98 to $39.6 \%$ (1.5 male articles per female article) in 2014-18. The female first authored article proportion increased in all broad fields over time, but at varying rates (Figure A1). There were relatively small increases in Mathematics, Multidisciplinary and in Biochemistry, Genetics and Molecular Biology but much larger increases in others, including more than doubling the proportion of female first authored articles in Business, Management \& Accounting, and almost tripling it in Energy. Thus, Prof Bar-llan entered a highly gendered profession and experienced a gradual but uneven reducing of gender disparities. 


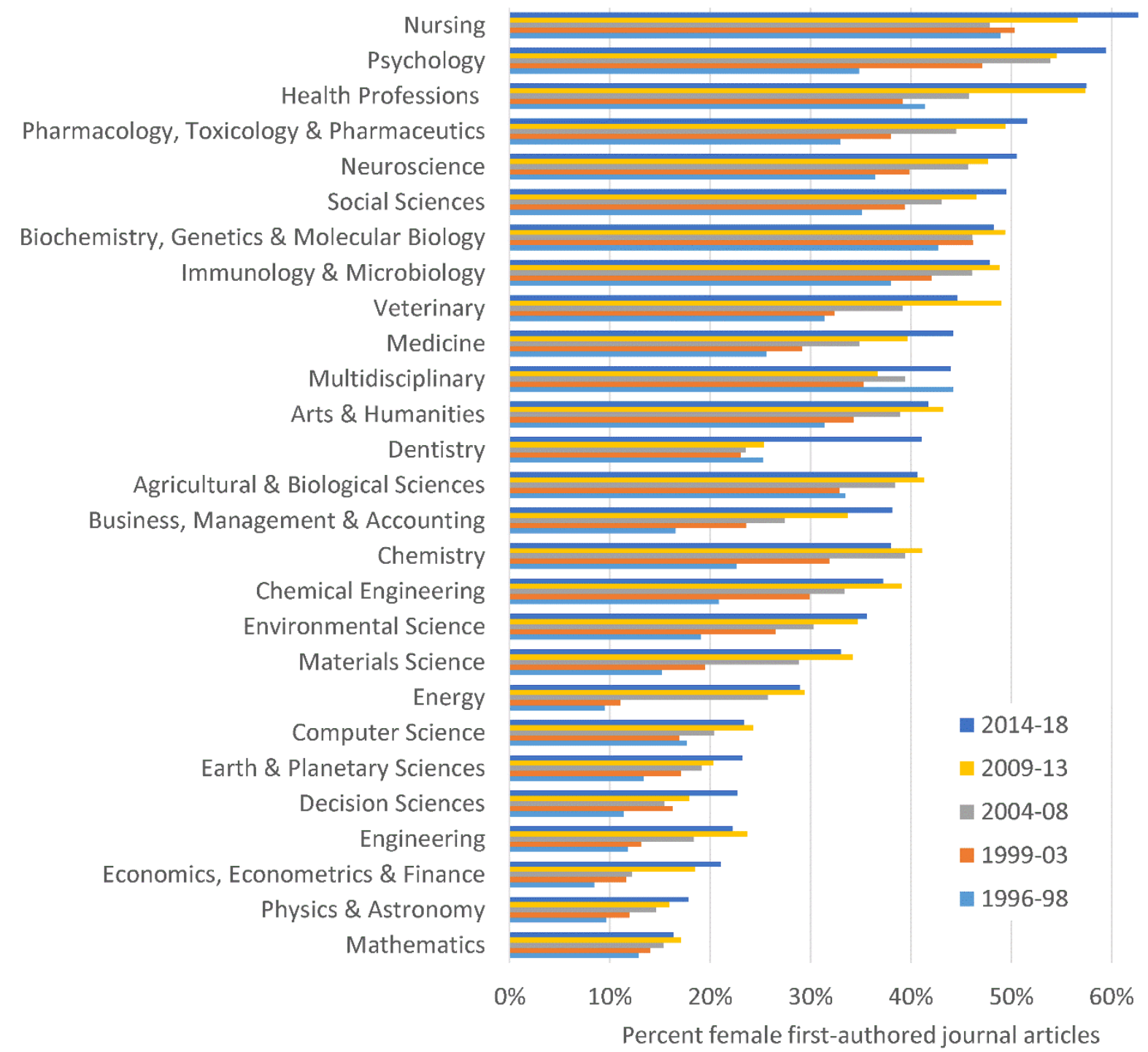

Figure A1. Percent of female first-authored journal articles out of all Scopus-indexed journal articles 1996-2018 with a first author affiliation of Israel, by broad Scopus field.

Professor Bar-llan's undergraduate background was in mathematics, which is the least female area in Israel, in terms of publishing. Most areas of mathematics experienced only small increases in the proportions of female first-authored research (Figure A2). 


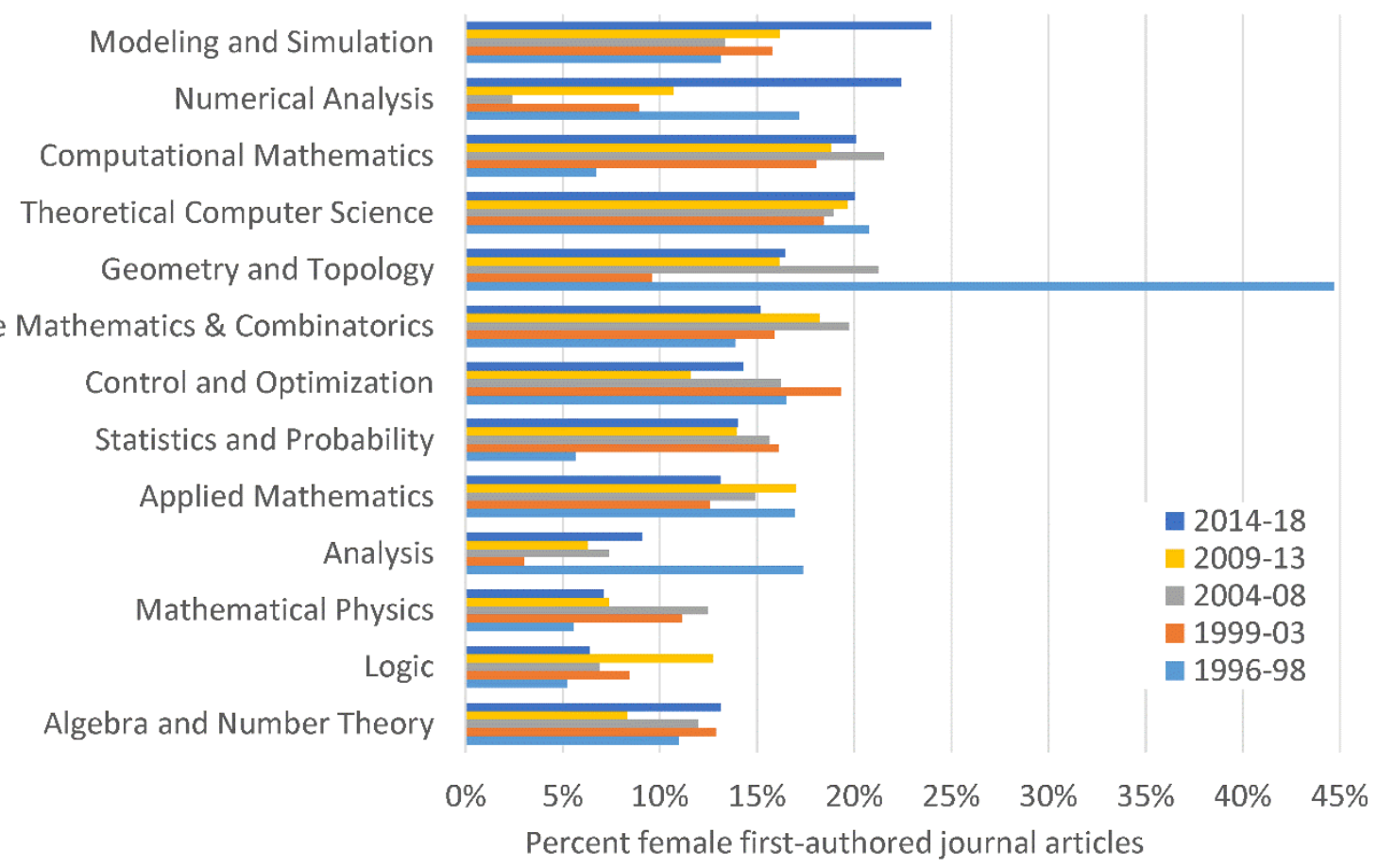

Figure A2. Percent of female first-authored journal articles out of all Scopus-indexed journal articles 1996-2018 with a first author affiliation of Israel, by narrow Scopus mathematics field.

Professor Bar-Ilan's PhD was mathematical computer science, another a male-dominated area. Within computing, only Human-Computer Interaction and Information Systems had strong increases in the proportion of female first-authored articles (Figure A3).

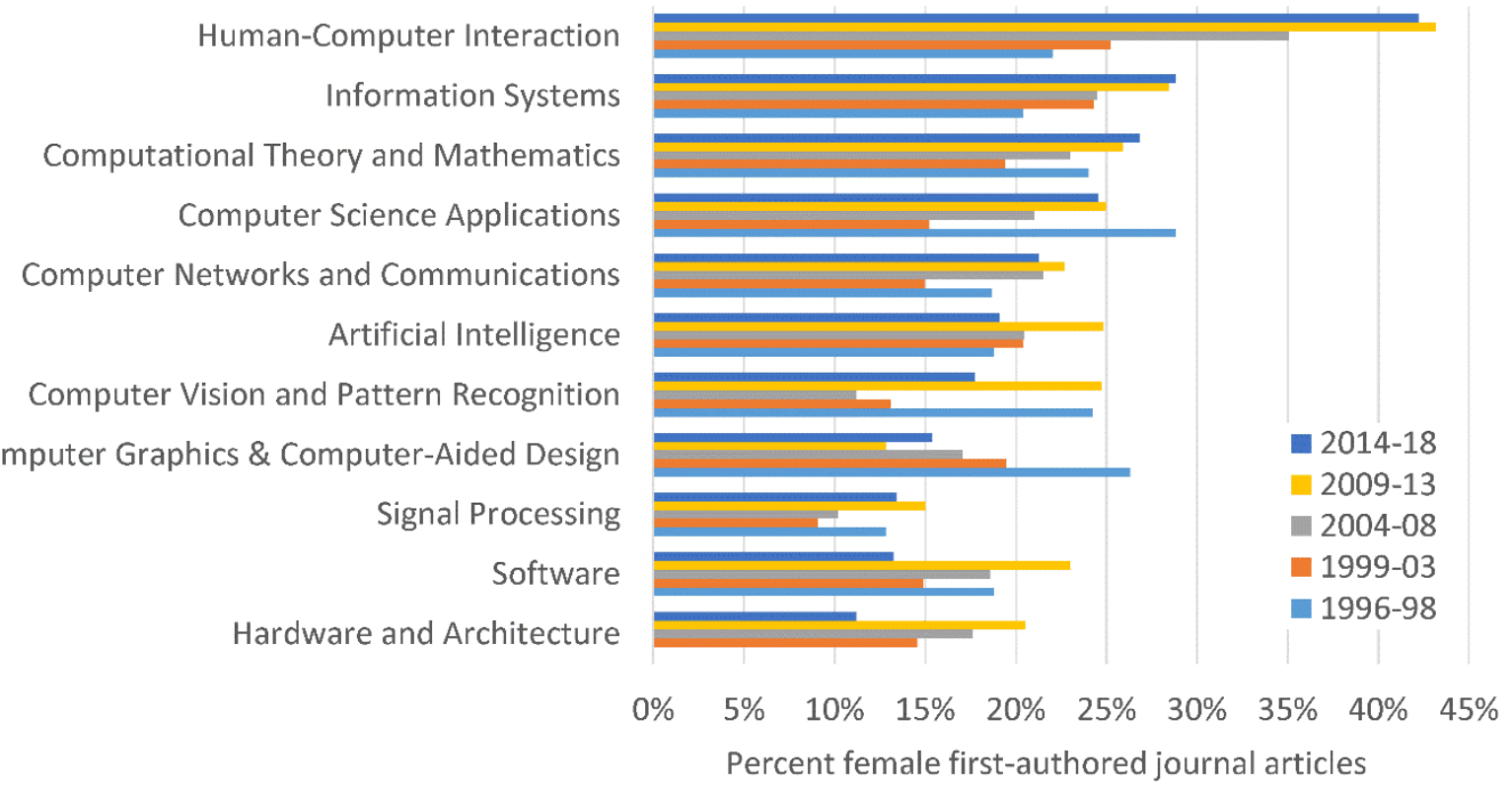

Figure A3. Percent of female first-authored journal articles out of all Scopus-indexed journal articles 1996-2018 with a first author affiliation of Israel, by narrow Scopus computing field.

Professor Bar-llan moved into library and information science shortly after her PhD, although she continued to conduct mathematical computer science research related to library and information science, with the topic of information retrieval. The social sciences in 1996-18 was one of the most gender-balanced areas and increased to achieve almost gender parity in 
publishing by 2014-18 (Figure 4). Library and Information Sciences is about average for gender parity amongst all social science fields in Scopus with a slow increase in the proportion of female first-authored articles.

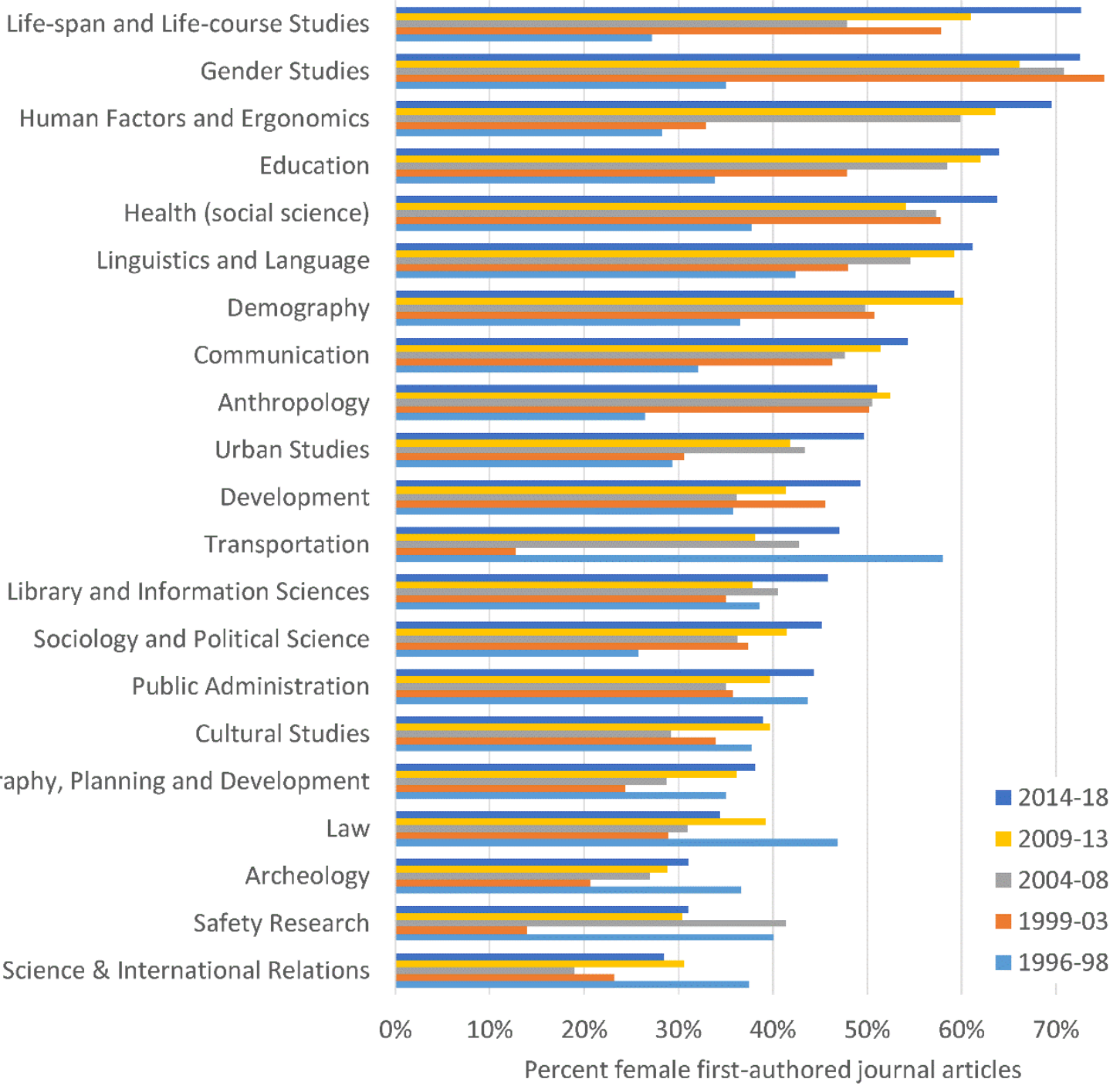

Figure A4. Percent of female first-authored journal articles out of all Scopus-indexed journal articles 1996-2018 with a first author affiliation of Israel, by narrow Scopus social science field.

In summary, Professor Judit Bar-llan physically (in terms of department) and partially intellectually (in terms of publishing) moved from the male dominated subject of Mathematics to more gender balanced Library and Information Sciences (45\% female firstauthored articles)during her career. Her physical move echoed the overall increase in gender balance of research in her home country, even though the fields that she worked in tended to have static gender compositions, at least in terms of publishing.

\section{Data and Methods}

Journal article records were extracted from Scopus for all papers with an institutional affiliation of Israel, and articles where the first author affiliation was not Israel were filtered out using the free Webometric Analyst Software. 
The first names of the first authors were extracted and submitted to Gender-API.com to estimate their genders. First names reported by Gender-API.com to be used at least $90 \%$ of the time by one gender were retained as gendered first names when the result was based on at least 10 gendered records found by Gender-API.com. The remaining first names were not used. Since male and female names may have different degrees of gendering and scarcity, a correction factor was calculated for any systematic bias. This was based on estimating the true proportion of male and female first authors by multiplying the number of articles with each first author name with the percentage of people having that first name for each gender, as reported by Gender-API.com. Totalling these gave an estimate of the total number of male (215142) and female (118508) first authors. Correction factors were then calculated by dividing this number by the number found using the gendered first names for males (173501) and females (88585), respectively. Thus, each gendered article found was multiplied by 1.240 for males and 1.338 for females, compensating for female names being marginally harder to identify.

Articles were categorised by their Scopus broad and narrow fields. The start year was chosen to be 1996 since the coverage of Scopus expanded in this year, although Prof Bar-llan began academic publishing in 1989. Scopus data from before 1996 is of a different character due to the lower coverage and so comparisons with later data could be misleading. 